\section{Alfalfa-based Organic Amendment in Peat-compost Growing Medium for Organic Tomato Transplant Production}

\author{
Ajay Nair, Mathieu Ngouajio ${ }^{1}$, and John Biernbaum \\ Department of Horticulture, Plant and Soil Science Building, Michigan \\ State University, A440-D Plant and Soil Sciences, East Lansing MI 48824
}

Additional index words. dairy compost, certified organic, EC, germination, media incubation, seedling, SPAD

\begin{abstract}
In the last decade, organic production has been the fastest growing segment in U.S. agriculture. With increase in organic acreages there is a strong and growing demand for organically grown transplants. As a result of limited commercial availability of certified vegetable transplants, growers often produce their transplants on-farm. Commercial organic mixes for organic transplant production may not be locally available and are usually expensive. Growers often design their own mixes using compost and other organic amendments. The purpose of this study was to evaluate the incorporation of alfalfa-based amendment in a peat-compost medium for organic tomato transplant production. Growing medium of 2 peat: 1 vermiculite: 1 compost (by volume) was amended with $0 \%, 0.6 \%, 1.2 \%$, $\mathbf{1 . 8 \%}$, or $\mathbf{2 . 4 \%}$ weight by weight of alfalfa-based organic amendment and incubated for 0,1 , 2, 3, or 4 weeks. Medium $\mathrm{pH}$ and electrical conductivity (EC), seed germination (untreated Solanum Lycopersicon L. 'Mountain Fresh' seed), transplant dry weight, height, stem diameter, and SPAD values were measured. Medium $\mathrm{pH}$ increased with addition of alfalfabased amendment but remained within the range of 5.5 to 7.0. Germination percentages were less than $50 \%$ in amended medium that was either not incubated or incubated for 4 weeks. Germination was greater than $75 \%$ if amended media were incubated for 1,2 , or 3 weeks. Seeds grown in peat-compost without any amendments had the highest germination rates; however, severe nutrient deficiency suppressed seedling growth. Relative to growth in medium with no amendments, plants growing in the amended medium had increased stem diameter, height, leaf chlorophyll content, and plant dry weight $(90 \%$ to $160 \%$ more $)$, provided the amended medium was incubated for at least 1 week. Application rate of $0.6 \%$ or $1.2 \%$ of alfalfa-based amendment produced transplants with suitable growth characteristics and met commercially acceptable standards for transplanting and handling at a reasonable estimated cost.
\end{abstract}

To optimize the production system, most vegetable crops are established from greenhouse-grown transplants. Transplant production is a critical phase that significantly affects growth and development of the crop in the field (Dufault, 1998). Some of the advantages of greenhouse-grown transplants are that they can be started early, have uniformity in growth, and are robust and have healthy root systems (Cantliffe, 1993). Production of transplants in small cells in peat-based medium is the most

\footnotetext{
Received for publication 5 Nov. 2010. Accepted for publication 11 Dec. 2010.

This paper is part of a dissertation by the senior author in partial fulfillment of the requirements for the Ph.D. degree.

This work was supported in part by Land O'Lakes Purina Feed, LLC, The Michigan Agricultural Experiment Station, and USDA grant \# 2005-5130002391.

We thank Dr. Renate Snider for a critical review of an early version of this manuscript.

The use of company or product in this publication does not imply any kind of endorsement.

${ }^{1}$ To whom reprint requests should be addressed; e-mail ngouajio@msu.edu.
}

common and widely practiced method (Raviv et al., 1986). To obtain healthy transplants, it is a common practice to fertilize medium with amendments or water-soluble fertilizers that provide nitrogen $(\mathrm{N})$, phosphorus $(\mathrm{P})$, potassium $(\mathrm{K})$, and other nutrients to the developing seedlings (Weston and Zandstra, 1989). The nutrient management aspect for conventionally grown transplants has been extensively researched and largely optimized; however, there are challenges for organic transplant production. There is little information available on aspects such as nutrient management in organic transplant production; as a result, organically produced transplants are often of low quality (Diaz-Perez et al., 2008). With increase in demand for organically grown transplants, a number of soluble organic fertilizers and supplements have emerged in the market (Kuepper and Everett, 2004; Treadwell et al., 2007). These products are usually expensive and not always locally available (Peet et al., 2008).

Growers often design their own mixes using compost and other organic amendments. to manage nutrient requirements of growing Organic growers largely depend on compost transplants. Incorporation of large proportions of compost in the growing medium is not warranted because it can lead to increased salinity and could adversely affect seed germination, seedling growth, and yield (Clark and Cavigelli, 2005; Sanchez-Monedero et al., 2004). Compost nutrient quality also varies based on raw materials used and process and duration of composting. Additionally, it is difficult to synchronize nitrogen mineralization from the compost-amended medium with crop N demand (Treadwell et al., 2007). Supplementing compost-amended medium with a standardized organic amendment serves as a viable alternative for nutrient management in organic transplant production. There are a number of organic $\mathrm{N}$ sources available such as alfalfa meal, soybean meal, and blood meal. Most of these amendments have not been tested thoroughly despite their popularity and widespread use by growers (Hochmuth et al., 2006). The addition of blood meal, rock phosphate, and greensand in the potting mix is practiced by many small-scale organic growers (Coleman, 1995). In most cases after incorporation of organic amendments, a certain period of time is required for $\mathrm{N}$ mineralization (Agehara and Warncke, 2005). In certain cases it is recommended that the plant-based amendment be mixed into the potting medium 2 weeks before sowing of seeds to prevent seed injury. We tested the use of a peat-compostbased growing mix supplemented with an alfalfa-based organic amendment derived from alfalfa, meat meal, molasses, and potash (Bradfield Organics ${ }^{\circledR}$ Tasty Tomato ${ }^{\mathrm{TM}}$ 3-3-3; Land O'Lakes Purina Feed LLC, Gray Summit, MO). The objectives of this study were to develop an efficient transplant production protocol by: 1) determining the optimal concentration of the alfalfa-based organic amendment; and 2) ascertaining the optimal incubation time of the medium with the amendment to ensure timely supply of nutrients and avoid seed or seedling injury.

\section{Materials and Methods}

The experiment was a $5 \times 5$ factorial with a completely randomized design. There were 25 growing medium treatments obtained through combination of five concentrations and five incubation periods of an alfalfa-based organic amendment (Bradfield Organics ${ }^{\circledR}$ Tasty Tomato $^{\mathrm{TM}}$ 3-3-3). The organic amendment is a coarse powder that has nutrients derived from alfalfa, meat meal, molasses, and sulfate of potash and contains essential nutrients (Table 1). The compost produced at the Michigan State University Student Organic Farm composed of: 1) straw and wood shaving from sheep and horse bedding; 2) 1- to 2-yearold leaf mold collected from campus; and 3) straw and hay formulated to produce a high carbon, low nitrogen mix for transplant production. The finished compost was maintained outside for 1 year and later stored in a heated greenhouse for another year so it was fully mature and dry. The compost had 27.5\% organic matter, $7.2 \mathrm{dS} \cdot \mathrm{m}^{-1}$ EC (in a $1: 1 \mathrm{v}: \mathrm{v}$ water extract), and $5.27 \mathrm{pH}$ (in a 1:1 v:v water 
extract). The nutrient content was $459,1,45$, $810,585,192,169$, and $235 \mathrm{mg} \cdot \mathrm{kg}^{-1}$ of nitrate$\mathrm{N}$, ammonium- $\mathrm{N}, \mathrm{P}, \mathrm{K}$, calcium, magnesium, sodium, and chlorine, respectively.

The first batch of root medium was prepared on 2 Apr. 2007 by mixing peat (Sunshine ${ }^{\circledR}$ Professional Grade; Sun Gro Horticulture Ltd., British Columbia, Canada), compost, and No. 2 vermiculite (Michigan Growers Products, Galesburg, MI) in the ratio 2:1:1 by volume. Water was added ( $40 \%$ of volume) to facilitate mixing and stimulate microbial activity. Moist bulk density of the medium was estimated at $1000 \mathrm{~kg} \cdot \mathrm{m}^{-3}$. A volume of $0.15 \mathrm{~m}^{3}$ of this medium was prepared and split into five sets of $0.03 \mathrm{~m}^{3}$ each. To four of these sets, one of the following amounts of organic amendment was assigned randomly: $168 \mathrm{~g}$ (equivalent to a rate of $10 \mathrm{lb} \cdot \mathrm{yd}^{-3}$ or $5.6 \mathrm{k} \cdot \mathrm{gm}^{-3}$ or $\left.0.6 \% \mathrm{w} / \mathrm{w}\right), 336 \mathrm{~g}$ $(1.2 \% \mathrm{w} / \mathrm{w}), 504 \mathrm{~g}(1.8 \% \mathrm{w} / \mathrm{w})$, and $672 \mathrm{~g}$ $(2.4 \% \mathrm{w} / \mathrm{w})$. No amendment was added to the last set that served as an unamended treatment. Sets of root medium were incubated for 4 weeks. Similarly, four more sets of five treatments were prepared and incubated for 3, 2, 1, and 0 weeks before seeding. Growing medium incubations were scheduled such that seeding for all media could take place the same day (30 Apr. 2007). Media were turned weekly to ensure aeration and uniformity. Air and medium temperatures were monitored during the incubation period using data logger sensors (WatchDog $^{\circledR}$; Spectrum Technologies, Plainfield, IL). Sensors were placed halfway inside the bucket, containing each medium, and outside to measure the ambient air temperature in the head house where media were stored. During the incubation phase, two medium subsamples were collected from treatments within the 4-week incubation treatment at weekly intervals to monitor $\mathrm{pH}$ and $\mathrm{EC}$ using a 1:1 and 1:2 (by volume) medium-to-water method, respectively (Watson and Brown, 1998).

After the incubation period, on 30 Apr. 2007, each treatment was filled uniformly into six 49-celled flats (98-celled flats cut in half) per treatment. Each flat was labeled and seeded with untreated tomato seeds (Solanum Lycopersicon L. 'Mountain Fresh') (Seedway LLC, Hall, NY). Flats were then moved into a heated greenhouse. The temperature inside the greenhouse was maintained at $22{ }^{\circ} \mathrm{C}$.

Table 1. Nutrient composition of alfalfa-based organic amendment incorporated in the growing media for organic transplant production (based on data provided by Bradfield Organics, Land O’Lakes Purina Feed LLC, Gray Summit, MO).

\begin{tabular}{lrlr}
\hline Nutrients & $\begin{array}{c}\text { Concn } \\
(\%)\end{array}$ & Nutrients & $\begin{array}{c}\text { Concn } \\
\left(\mathrm{mg} \cdot \mathrm{kg}^{-1}\right)\end{array}$ \\
\hline Nitrogen & 3.0 & Iron & 425.0 \\
Phosphorus & 1.3 & Manganese & 65.0 \\
Potassium & 3.0 & Zinc & 75.0 \\
Sulfur & 0.8 & Copper & 20.0 \\
Calcium & 2.8 & Cobalt & 0.9 \\
Magnesium & 0.3 & Boron & 13.9 \\
Sodium & 0.3 & Selenium & $<5.0$ \\
Chlorine & 0.4 & - & - \\
Protein & 19.0 & - & - \\
Fat & 3.5 & - & - \\
Fiber & 14.0 & - & - \\
Sugar & 6.5 & - & - \\
\hline
\end{tabular}

Irrigation was carried out by overhead hoses and breakers with minimal water to avoid leaching of nutrients from medium. Medium was irrigated frequently for the first week to provide constant moisture supply to facilitate seed germinating. Germination in 49 cells was assessed 2 weeks after seeding by counting emerged seedlings. Destructive sampling was carried out at two different growth stages (2 and 6 weeks after seeding) to determine total dry weight (root and shoot dry weight). Sample size for destructive sampling consisted of five transplants per treatment with six replications. Transplants were gently pulled out, and roots were washed under running water to remove the medium. Plant height, stem diameter, and chlorophyll content were also measured. Stem diameter was measured just above the point of attachment of cotyledons using a Vernier caliper (Avenger Products, Boulder City, NV). Leaf chlorophyll content of the recently emerged, fully opened true leaf was recorded with a chlorophyll meter (SPAD-502 Chlorophyll Meter; Minolta Camera Co. Ltd., Osaka, Japan). The SPAD values were means of 10 leaf measurements. Before seeding and 2 weeks after seeding, medium samples were collected from all treatments to measure $\mathrm{pH}$ and $\mathrm{EC}$. The entire experiment was repeated concurrently in a separate greenhouse. Statistical analyses were conducted using SAS Statistical Software (SAS Version 9.1; SAS Institute Inc., Cary, NC). Data were subjected to simple linear regression analysis using analysis of covariance with amendment rate as the covariate. Means were separated at various covariate levels by "lsmeans" and "pdiff" statements in SAS ( $P \leq 0.05$ level). Seed germination and stem diameter data were analyzed by nonlinear regression analysis using the following logistic equation:

$$
y=(a+c x) /(1+b x)
$$

where $y$ is the dependent variable; $x$ the amendment concentration; and $a, b$, and $c$ are the regression parameters.

\section{Results and Discussion}

Medium characteristics. Over the course of the 4-week incubation period, medium EC increased between 3-week and 4-week incubation. For unamended medium, there was initially a gradual decrease in EC during the second and third weeks of incubation followed by an increase by the end of 4 weeks (Fig. 1A). Electrolytic conductivity values, by the end of 4-week incubation period, for
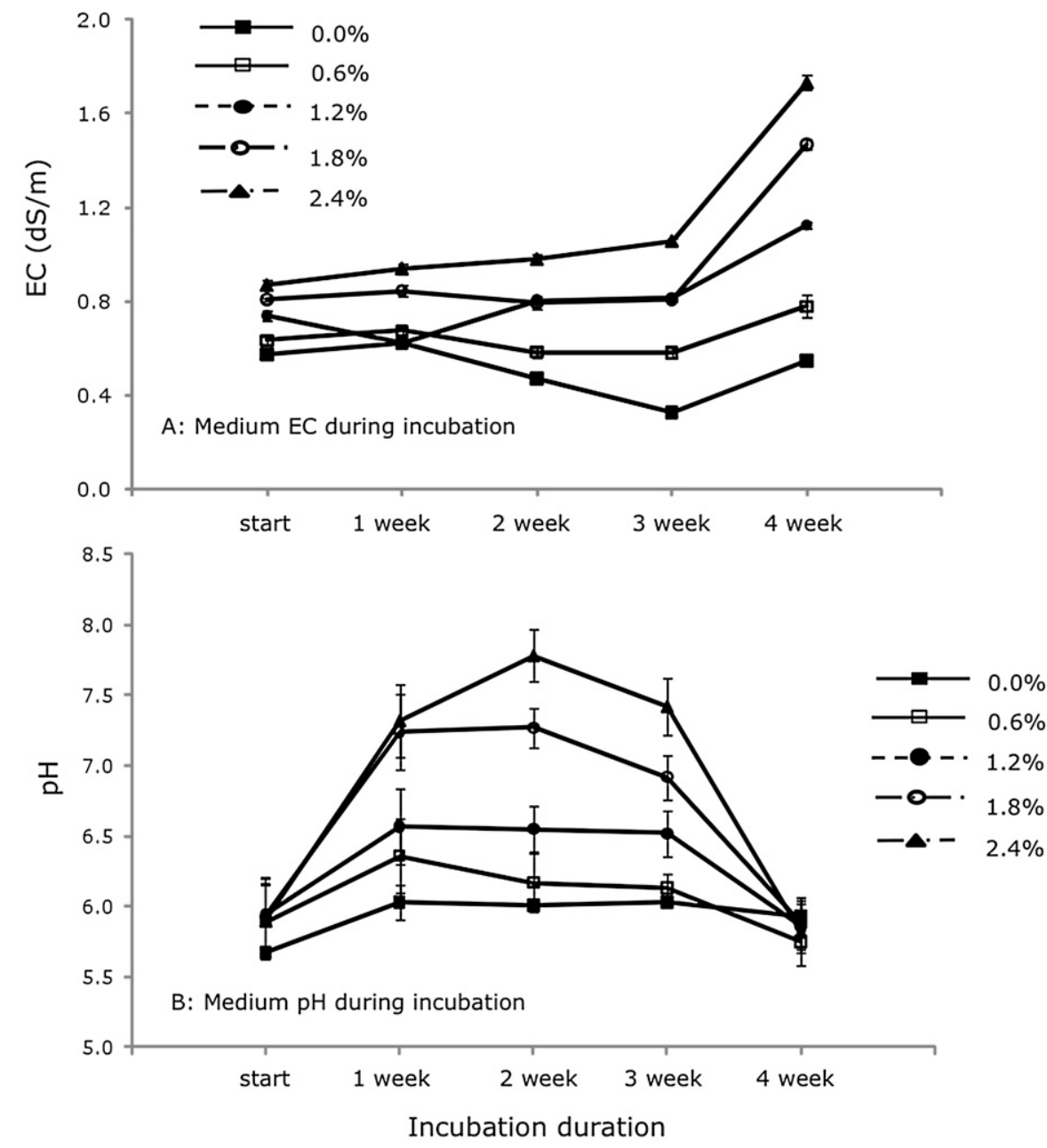

Fig. 1. Changes in media electrical conductivity (A) and $\mathrm{pH}$ (B) during a 4-week incubation period with different amendment concentrations. Data collected from the 4-week incubation treatment only. Each data point is a mean of two samples. Error bars denote SE. 
all media treatments, except the unamended treatment, were higher than values at the start of the incubation. Increase in EC with increasing incubation is attributable partly to the presence of potassium sulfate in the amendment and to the release of soluble compounds from the mineralization and nitrification process as a result of prolonged incubation. Differences in EC values were largest at the end of 4-week incubation in which medium with higher amendment rates exhibited higher values. Medium $\mathrm{pH}$ increased for the first 2 consecutive weeks of incubation, after which it started to decrease (Fig. 1B). Interestingly, irrespective of the rate, at the end of the incubation, all treatments had similar $\mathrm{pH}$ values. Medium $\mathrm{pH}$ ranged from 5.2 to 6.3 , a suggested optimal range for a greenhouse substrate (Herrera et al., 2008; Sanchez-Monedero et al., 2004; Warncke and Krauskopf, 1983).

For the first 2 weeks of incubation, temperatures for amended media were 2 to $4{ }^{\circ} \mathrm{C}$ higher than the unamended medium (Fig. 2). Increase in temperature after addition of a similar product to mature compost in a bioreactor, followed by incubation, has been reported by Jost (2008). Higher concentrations of alfalfabased amendment resulted in higher medium temperatures. After 2 weeks, the difference in medium temperature among treatments gradually disappeared.

Seed germination. Data from both greenhouses were combined as a result of lack of interaction between greenhouses and treatments. Seed germination was significantly affected by amendment concentration and weeks of incubation. The effect of amendment concentration varied depending on incubation period. For unamended medium ( $0 \%$ amendment), incubation time did not have a profound effect on seed germination (Fig. 3). Unincubated, 1-, 2-, or 3-week incubated medium had no difference in seed germination; however, 4-week incubated medium had lower germination. Differences in germination became more evident with the addition of alfalfa-based amendment. At $0.6 \%$ amendment concentration, the lowest germination $(28 \%)$ was recorded for unincubated medium followed by the 4-week incubation treatment (46\%). A similar trend was observed at $1.2 \%, 1.8 \%$, and $2.4 \%$ amendment concentrations. Lowest seed germination $(6 \%)$ was recorded for the unincubated $2.4 \%$ amendment treatment. Among all incubation treatments, the highest seed germination was obtained when no amendment was added to the medium. It is evident that addition of the amendment was affecting seed germination, but this was true only when the medium was either unincubated or incubated for 4 weeks. Within unincubated and 4-week incubation treatments, drop in seed germination was sharp with increasing rates of amendment concentration. The reduction in seed germination resulting from the addition of amendment was counteracted by incubating the amended medium for 1,2 , or 3 weeks. To obtain satisfactory germination when incorporating the organic amendment, it is critical to incubate the medium for a minimum of 1 week and

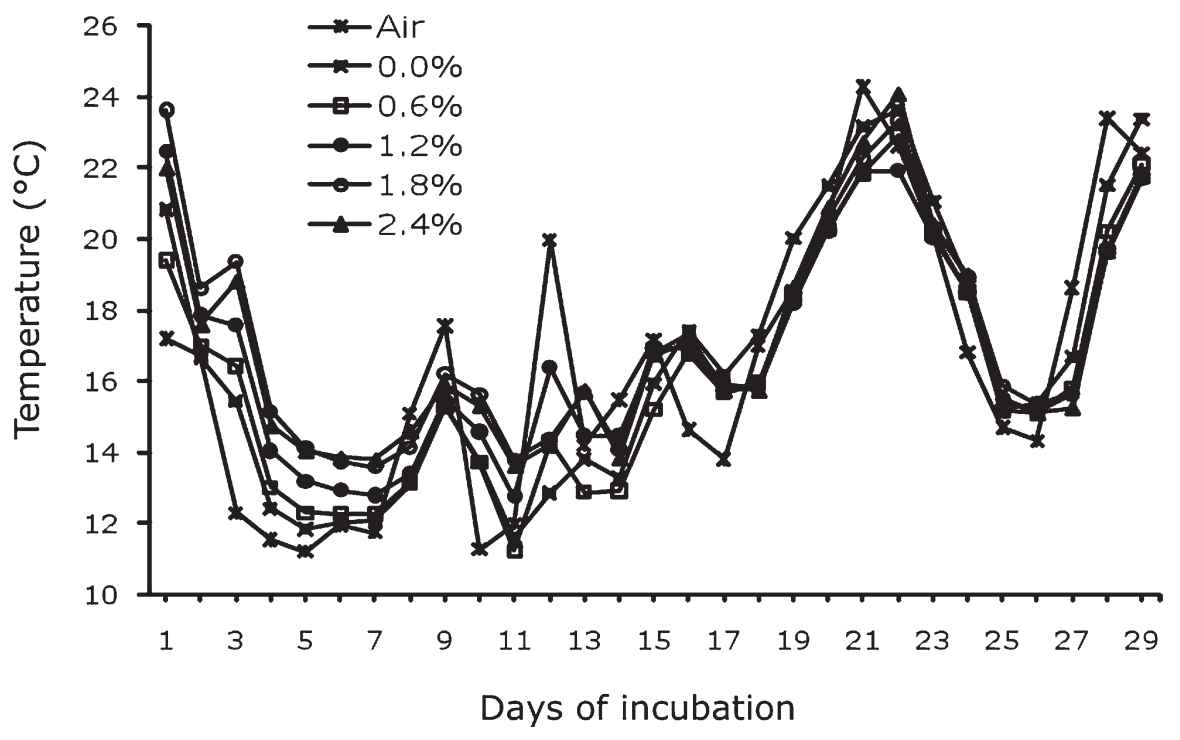

Fig. 2. Temperatures of ambient air and media (amended with $0 \%, 0.6 \%, 1.2 \%, 1.8 \%$, or $2.4 \%$ alfalfabased organic amendment) during a 4-week incubation period. Media were incubated in buckets with loose lids and temperature sensors placed in the middle.

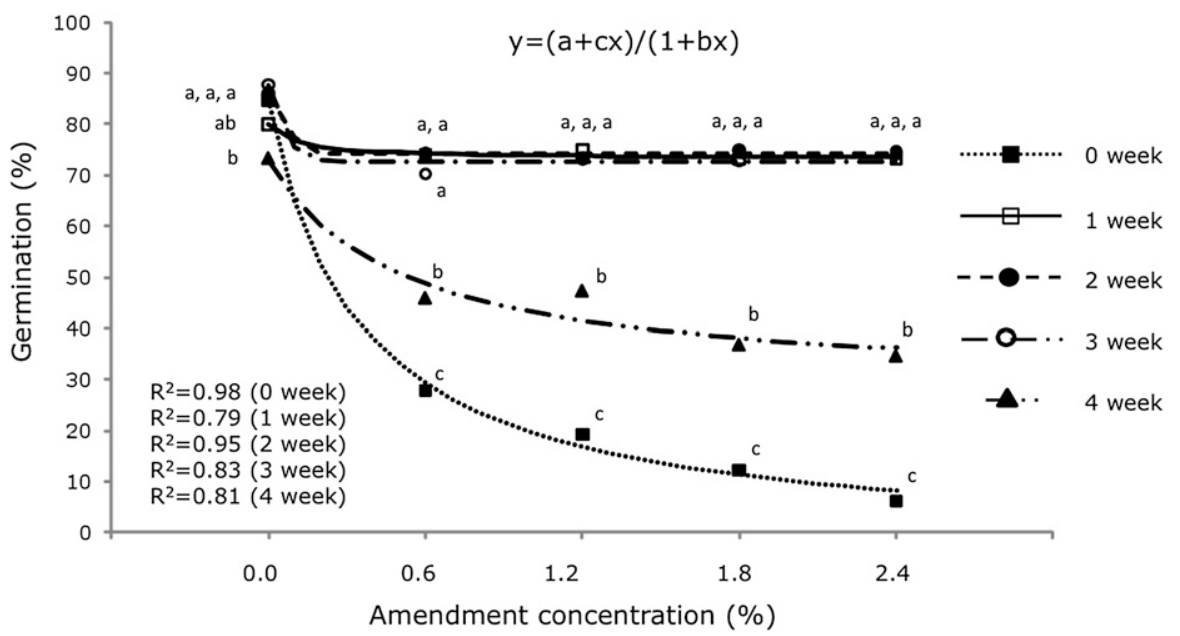

Fig. 3. Effects of alfalfa-based organic amendment in peat-compost growing medium on tomato seed germination 2 weeks after seeding as analyzed by non-linear regression. Mean separation between incubation periods at any given concentration by lowercase letter(s). Values with same letter(s) are not significantly different $(P \leq 0.05)$.

a maximum of 3 weeks before seeding, based on the incubation temperature used in this study. It is important to note that the required incubation time is likely a function of temperature and could be shorter at higher temperature or longer at lower temperature than the average temperature of $18{ }^{\circ} \mathrm{C}$ in this experiment. Organic mixes containing plant- and animal-based residues could lower tomato seed germination and should be carefully tested to ensure adequate germination (Peet et al., 2008). Studies on plant- and animal-based amendments suggest incubation of amended medium for at least 2 weeks before sowing to prevent injury or damage to seed (Koller et al., 2004). The period of incubation also may depend on other factors such as aeration. The better the aeration, the shorter the incubation needed (Jost, 2008).

Theis (2005) observed lowest tomato seedling emergence if a peat and vermiculite me- dium was amended with alfalfa meal as compared with the same medium amended with composted dairy manure, dairy manurebased vermicompost, or sesame meal. Poor germination in media treatments that were amended and unincubated could be a result of presence of allelochemicals or a harmful microbial environment. Electrolytic conductivity also plays an important role in germination, and elevated EC is known to restrict germination and growth of tomato seedlings (Cuartero and Fernandez-Munoz, 1999; Foolad and Jones, 1991). Higher salinity could not only lower germination, but also lengthen the time needed for germination (Ayers, 1952). In our study, however, EC remained below $2 \mathrm{dS} \cdot \mathrm{m}^{-1}$, which is lower than values that affect tomato seed germination (Herrera et al., 2008; Ramana et al., 2002). Before seeding, differences in medium EC among incubation treatments were less evident in the unamended 
and $0.6 \%$ amendment medium, but with increasing amendment concentration, longer incubation treatments exhibited higher EC values (Fig. 4A). Those differences, however, narrowed down 2 weeks after seeding. Overall there was a strong linear relationship with medium EC increasing with increasing amendment concentration for every incubation period (Fig. 4B). Before seeding, with respect to medium $\mathrm{pH}$, unamended medium treatments had lower $\mathrm{pH}$ than amended medium, except for the 4-week incubation treatment (Fig. 5A). Medium pH for 4-week incubation did not increase with increasing amendment rates and did not fit the regression analysis as good as other treatments. Two weeks after seeding, within any incubation period, higher $\mathrm{pHs}$ were recorded for unamended media (Fig. 5B). In general, most of the treatments tested in this study had $\mathrm{pH}$ values in the acceptable range of 5.2 to 6.5 either before or 2 weeks after seeding.

Allelopathic effects of alfalfa plant residues on emergence and growth of seedlings have been reported. Alfalfa extracts inhibited seed germination in cotton (Megie et al., 1967), corn (Guenzi et al., 1964), and cucumber (Ells and McSay, 1991). Biological activity possibly could contribute to poor germination in the unincubated medium. Considerable microbial activity, in the form of a thick mycelial growth, was observed on the medium surface within 1 week of incorporation of the amendment. Concentration of fungal mycelia increased with increasing rate of the amendment and was accompanied by a distinct butyric smell. Analysis of 1-week incubated medium at Michigan State University Plant Diagnostics Laboratory indicated the presence of fungi, the dominant form being Cephalosporium sp. There is no available literature citing Cephalosporium as a causal organism affecting tomato seed germination; however, proliferation of fungus, triggered by the alfalfa-based amendment, could have rotted the seeds. Poor germination in 4-week incubated media can be largely attributed to higher microbial activity and accumulation of harmful organic acids and compounds produced as a result of mineralization.

Transplant biomass. There were no differences in total transplant dry weight (root and shoot) 2 weeks after seeding; however, differences were significant 6 weeks after seeding. Unamended treatments had the lowest transplant dry weight accumulation indicating that the compost used in this study, and under the irrigation methods used, could not adequately supply nutrients up to the final stage in the greenhouse ( 6 to 8 weeks). Com-
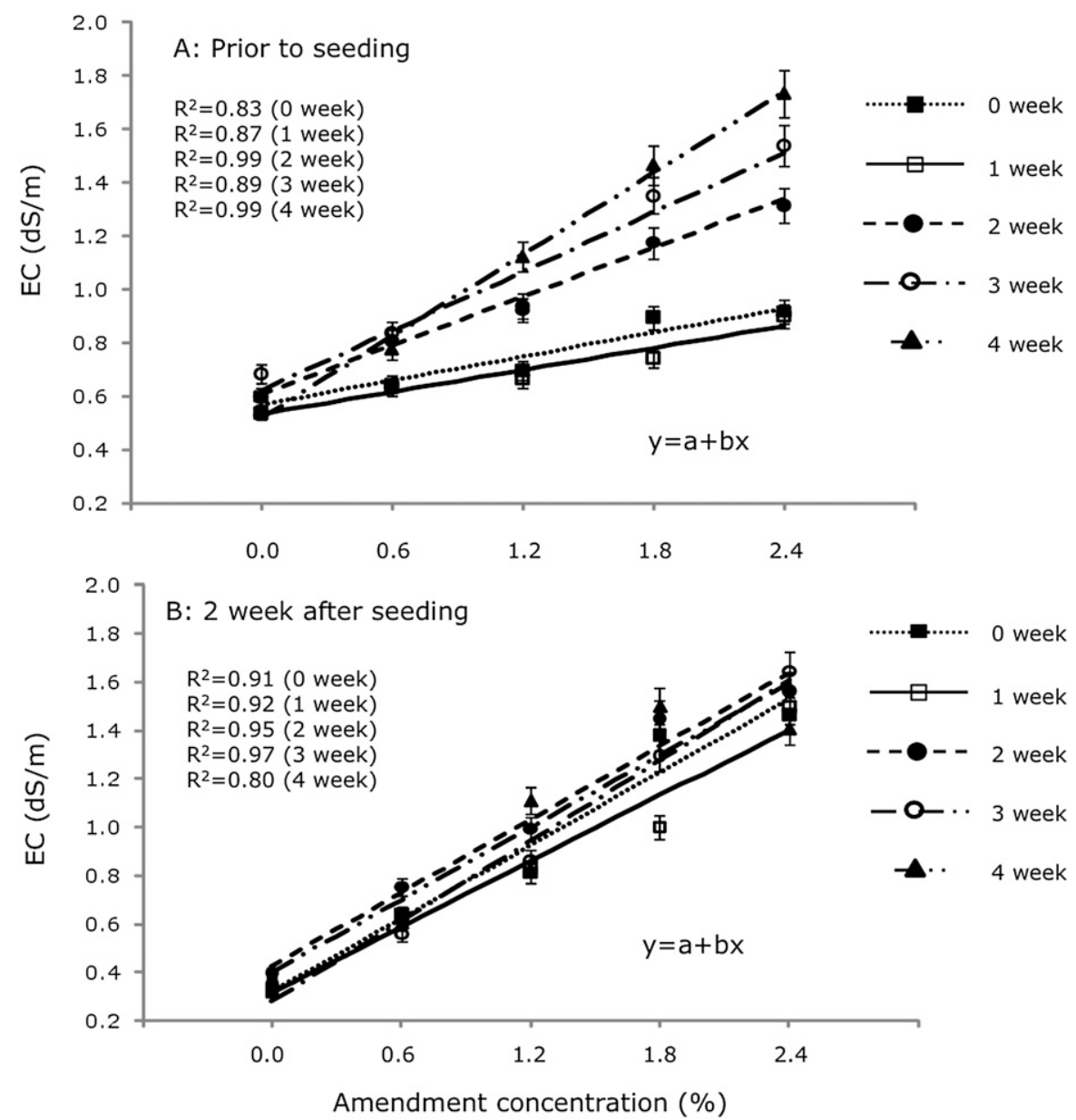

Fig. 4. Effects of alfalfa-based organic amendment in peat-compost growing medium on medium electrical conductivity before seeding (A) and 2 weeks after seeding (B) as analyzed by simple linear regression. Error bars denote SE. post was $25 \%$ of the medium by volume. To increase the long-term nutritional content of the medium, there is a possibility of increasing the proportion of compost in the medium, but that action could lead to problems associated with higher salt concentration, poor physical characteristics, contamination, and low seed germination (Garcia-Gomez et al., 2002; Perez-Murcia et al., 2005; Raviv et al., 1986).

An increased amount of amendment in the medium translated to healthier transplants with $90 \%$ to $150 \%$ more transplant dry weight than plants growing in unamended medium. As a result of poor germination, no data could be collected for medium to which amendment was added and left unincubated ( 0 -week incubation). Transplant dry weight increased as amendment rate increased, but the rate of increase was not the same between incubation periods (Fig. 6). Simple linear regression analysis explained trends for different incubation periods. Analysis of covariance with amendment concentration as the covariate revealed differences in regression slope coefficients $(P \leq 0.0001)$. The regression slope for unincubated medium was statistically similar to 1- or 2-week incubations; however, it was different when compared with 4-week incubation $(P \leq 0.0001)$. Slopes for 2-, 3-, or 4-week incubations were statistically different. Unamended treatment incubated for 1, 2 , or 3 weeks produced transplants with higher dry weight than 4 -week incubation. At $0.6 \%$ amendment concentration, 2-, 3-, or 4-week incubation produced higher transplant dry weight as compared to 1 -week incubation. At higher amendment concentrations $(1.2 \%$, $1.8 \%$, or $2.4 \%$ ), 4 -week incubation produced transplants with the highest dry weight. This could be a result of enhanced nutrient availability in 4-week incubated medium as a result of increased mineralization during incubation.

The highest transplant dry weight was obtained with medium amended with $2.4 \%$ amendment and incubated for 4 weeks. Although this treatment produced the highest transplant dry weight, germination results for 4-week incubation were lower than all other incubation treatments irrespective of amendment concentrations. The higher per plant dry weight in the 4-week incubation may be an effect of lower plant density resulting from void spaces created in flats by ungerminated seeds and the higher availability of nutrients per plant.

Stem diameter, height, and chlorophyll content. The effect of amendment concentration and incubation period on stem diameter was explained by non-linear regression (Fig. 7). Regression lines displayed strong coefficient of determination values and accounted for differences in medium resulting from different amendment concentrations and incubation periods. At $0.6 \%$ amendment concentration, there was a sharp increase in stem diameter for every incubation period. Subsequent addition of amendment did not increase stem diameter considerably. Unamended treatments in all incubation periods exhibited small stem diameters. For unamended medium, 2-, 3-, or 4-week incubations produced seedlings with 

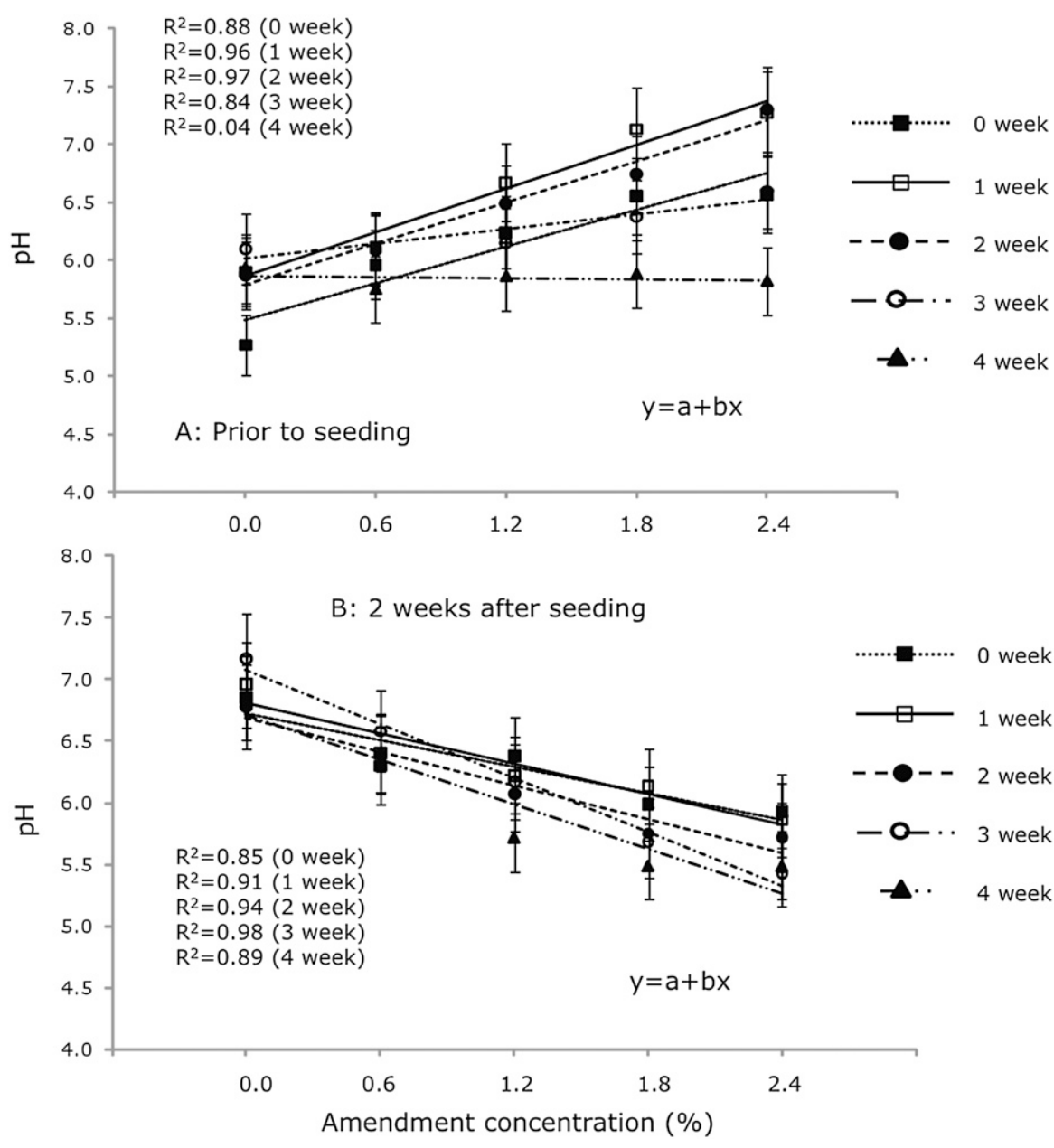

Fig. 5. Effects of alfalfa-based organic amendment in peat-compost growing medium on medium $\mathrm{pH}$ before seeding (A) and 2 weeks after seeding (B) as analyzed by simple linear regression. Error bars denote SE.

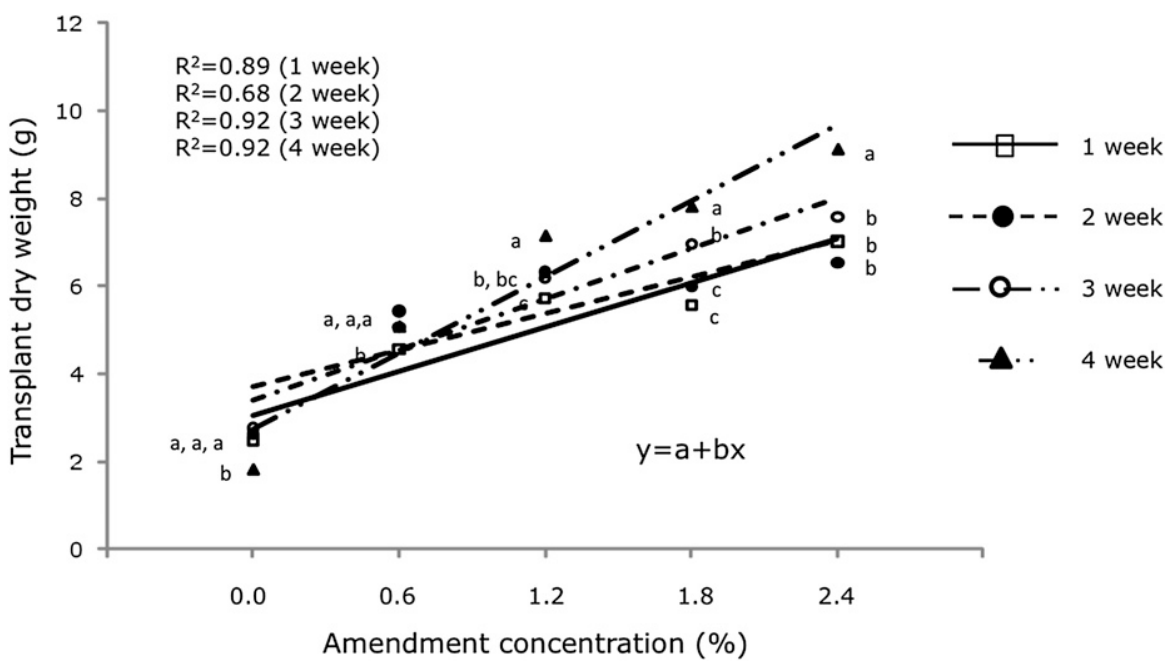

Fig. 6. Effects of alfalfa-based organic amendment in peat-compost growing medium on tomato transplant biomass 6 weeks after seeding as analyzed by simple linear regression. Mean separation between incubation periods at any given concentration by lowercase letter(s). Values with same letter(s) are not significantly different $(P \leq 0.05)$.

larger stem diameters than 1-week incubation, because longer incubation resulted in enhanced mineralization of compost (part of the base medium) in those treatments. A number et al., 2004). Addition of nutrients from the amendments led to increased stem diameters compared with unamended treatments, showcasing benefits to transplant growth.

Various studies demonstrated that mineral nutrition of tomato seedlings influences plant growth at the transplant and post-transplant stages (Melton and Dufault, 1991; Weston and Zandstra, 1989). Liptay et al. (1992) reported increasing tomato transplant heights with increasing $\mathrm{N}$ levels. No comparisons for transplant height could be made for unincubated treatments as a result of lack of transplants resulting from poor germination. Overall, transplant height increased with increasing amendment rates for all incubations (Fig. 8A). The response was linear with different degrees of slope. In the unamended medium, transplant heights were similar for 1- and 4week incubations. Transplant height for 2- or 3 -week incubation was higher than 1 or 4 weeks. At $1.2 \%$ and $1.8 \%$ amendment concentration, 2- and 3-week incubation treatments produced transplants with the highest heights, respectively. For 2-week incubation treatment, transplant height increased with the increase in the amendment concentration up to the $1.2 \%$ level, after which it decreased. For the 3 -week incubation treatment, $1.8 \%$ or $2.4 \%$ amendment treatments produced taller transplants.

A direct link has been demonstrated between leaf chlorophyll content (measured indirectly through the SPAD meter) and leaf $\mathrm{N}$ status (Li et al., 1998; Swiader and Moore, 2002; Wang et al., 2004). Leaf greenness or chlorophyll content is affected by several factors, including nutrient concentration, distribution of chlorophyll in leaves, and plant genotype (Soval-Villa et al., 2002; Uddling et al., 2007). In general, SPAD values increased with increasing rates of amendment (Fig. 8B). This is the result of increased nutrient concentration in the growing medium. Studies have reported increased plant height, leaf number, leaf area, and plant dry weight with increased levels of $\mathrm{N}$ concentration in the growing medium (Masson et al., 1991; Weston and Zandstra, 1989). Duration of incubation did influence SPAD values at the $0 \%$ or $2.4 \%$ amendment level. At $0 \%$ amendment concentration, 2-week incubation had the lowest SPAD value followed by 4 -week treatment. There was no difference between 1- and 3-week incubation treatment, which was higher than 2- or 4-week treatment. Differences were less evident at the $0.6 \%, 1.2 \%$, or $1.8 \%$ amendment level; however, at the $2.4 \%$ amendment level, 4-week incubation had the lowest SPAD value.

The compost and peat-based medium amended with alfalfa-based amendment produced healthy tomato transplants from direct seeding if incubation of the amended medium occurred for 1, 2, or 3 weeks. Koller et al. (2004) used several plant- and animal-based fertilizers for vegetable transplant production and recommended mixing and incubating plant-based amendments with potting medium for 2 weeks to prevent seed damage. The organic amendment used in this study 


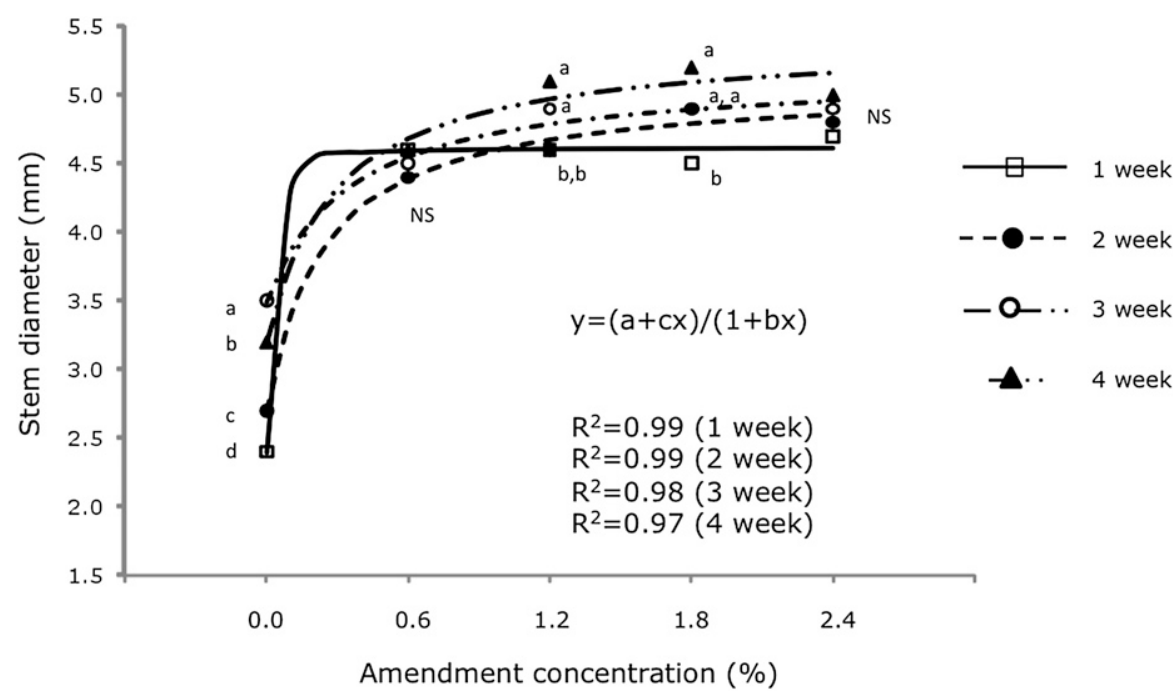

Fig. 7. Effects of alfalfa-based organic amendment in peat-compost growing medium on tomato transplant stem diameter 6 weeks after seeding as analyzed by non-linear regression. Mean separation between incubation periods at any given concentration by lowercase letter(s). Values with same letter(s) are not significantly different $(P \leq 0.05)$. NS $=$ means are not significantly different.
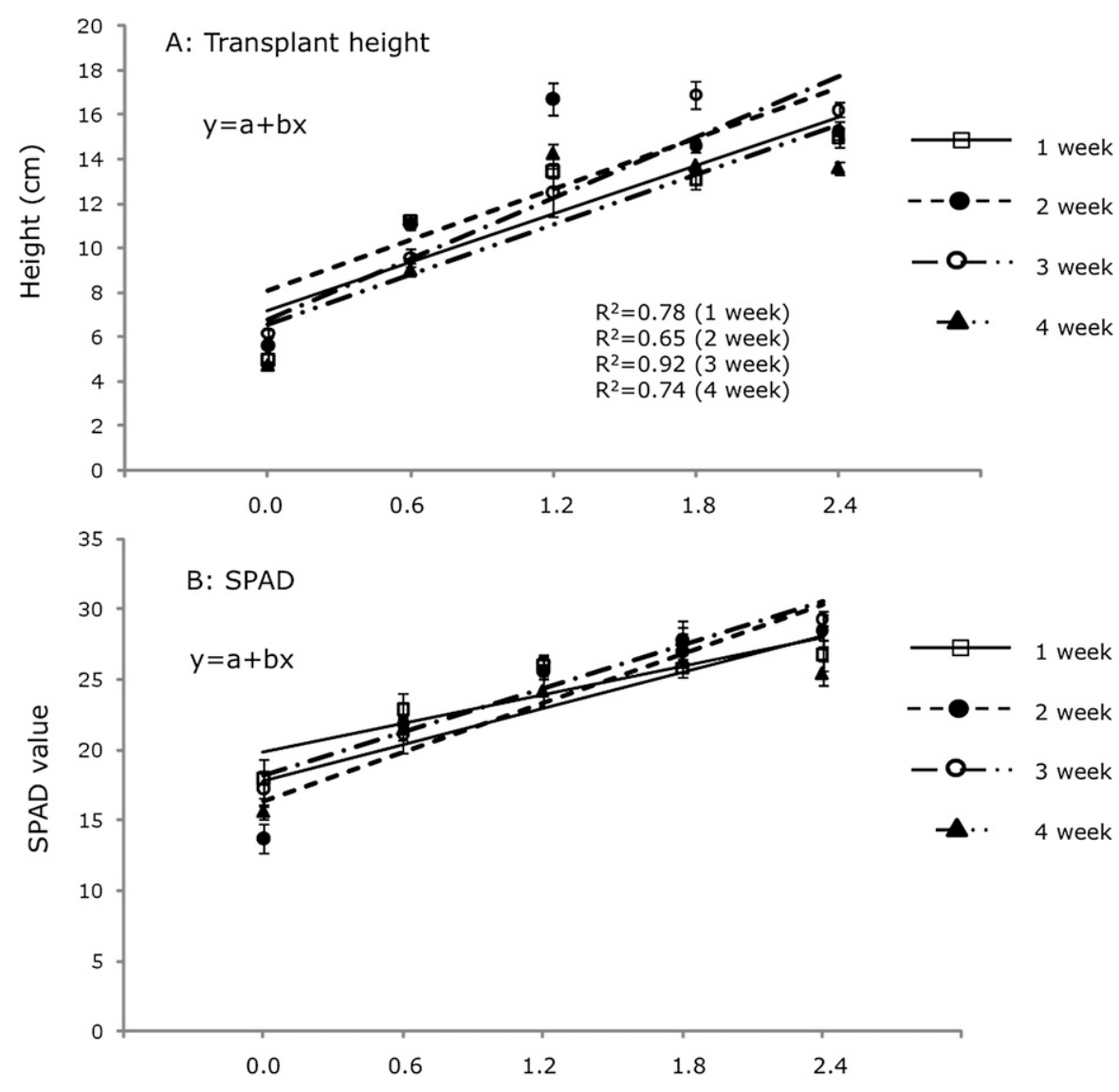

Amendment concentration (\%)

Fig. 8. Effects of alfalfa-based organic amendment in peat-compost growing medium on tomato transplant height (A) and chlorophyll content (SPAD value) (B) as analyzed by simple linear regression. Error bars denote SE.

was derived from alfalfa, molasses, and meat meal, and it is recommended that the amendment be incubated with the growing medium before seeding. This process also allows mineralization and release of nutrients from the amendment before seeding. Incubation also will prevent allelopathic interactions between amendment and the germinating seedlings. Allelopathic effects of alfalfa plant residue on seed germination and growth of cucumber seedlings have been reported (Ells and McSay, 1991).

Selection of a particular kind and rate of organic amendment should be made based on cost-effectiveness and effects on medium $\mathrm{pH}$ and EC, seed germination, plant height, stem diameter, chlorophyll content, plant biomass, and sustainability of the product. To balance all those variables without compromising transplant health and quality would be the optimum approach to organic transplant production. Overall, growing medium amended with $0.6 \%, 1.2 \%, 1.8 \%$, or $2.4 \%$ concentration of alfalfa-based amendment produced transplants with suitable growth characteristics and met commercially acceptable standards for transplanting and handling. A higher rate of $2.4 \%$ amendment produced robust and healthy transplants but has the potential to affect seed germination and thereby needs prolonged incubation.

From a grower's standpoint, feasibility for the adoption of any production system or technique is often driven by cost of production. Use of alfalfa-based amendment tested in this study was economically feasible. The unamended medium used in this study would cost $\$ 67 / \mathrm{m}^{3}$, assuming peat at $\$ 36\left(0.5 \mathrm{~m}^{3}\right.$ at $\left.\$ 71 / \mathrm{m}^{3}\right)$, vermiculite at $\$ 24\left(0.25 \mathrm{~m}^{3}\right.$ at $\$ 95 /$ $\left.\mathrm{m}^{3}\right)$, and compost at $\$ 7\left(0.25 \mathrm{~m}^{3}\right.$ at $\left.\$ 26 / \mathrm{m}^{3}\right)$. Depending on geographical location in the United States, price for dairy compost can vary from $\$ 16$ to $66 / \mathrm{m}^{3}$ (McEntee, 2005). In case of certified organic medium, it is not unusual for commercial seedling and transplant medium to cost $\$ 60$ to $\$ 197 / \mathrm{m}^{3}$ or more. Based on retail purchase of a single bag (11 kg), an estimated cost of the amendment (Bradfield Organics ${ }^{\circledR}$ Tasty Tomato 3-3-3) used is $\$ 20$. If the product is used at $0.6 \%$ concentration (at a rate of $5.9 \mathrm{~kg} \cdot \mathrm{m}^{-3}$ ), it would cost $\$ 10 / \mathrm{m}^{3}$, which would increase medium cost from $\$ 67$ to $\$ 77 / \mathrm{m}^{3}$ (an increase of $15 \%$ ). Even then, input cost for the medium is well within prevailing market value of other commercial organic blends and formulations. There are benefits to incorporation of alfalfa-based amendments in compost-based medium when compost alone (at $25 \%$ volume) was not able to provide sufficient nutrition for the desired transplant growth. Thus, use of plant- and animal-based amendments such as organic amendment used in this study, together with compost, has the potential to serve as nutrition supplements for sustainable greenhouse transplant production.

\section{Literature Cited}

Agehara, S. and D.D. Warncke. 2005. Soil moisture and temperature effects on nitrogen release from organic nitrogen sources. Soil Sci. Soc. Amer. J. 69:1844-1855.

Ayers, A.D. 1952. Seed germination is affected by soil moisture and salinity. Agron. J. 44:82-84.

Bustamante, M.A., C. Paredes, R. Moral, E. Agullo, M.D. Perez-Murcia, and M. Abad. 2008. Compost from distillery wastes as peat substitutes for transplant production. Resour. Conserv. Recycling 52:792-799.

Cantliffe, D.J. 1993. Pre- and postharvest practices for improved vegetable transplant quality. HortTechnology 3:415-418. 
Clark, S. and M. Cavigelli. 2005. Suitability of composts as potting media for production of organic vegetable transplants. Compost Sci. Util. 13:150-156.

Coleman, E. 1995. The new organic grower. Chelsea Green Publishing Co., White River Junction, VT.

Cuartero, J. and R. Fernandez-Munoz. 1999. Tomato and salinity. Sci. Hort. 78:83-125.

Diaz-Perez, J.C., J. Silvoy, S.C. Phatak, D.S Pitchay, and R. Morse. 2008. Organic tomato transplant production in compost-amended substrate. Acta Hort. 782:241-243.

Dufault, R.J. 1998. Vegetable transplant nutrition. HortTechnology 8:515-523.

Ells, J.E. and A.E. McSay. 1991. Allelopathic effects of alfalfa plant residues on emergence and growth of cucumber seedlings. HortScience 26:368-370.

Foolad, M.R. and R.A. Jones. 1991. Genetic analysis of salt tolerance during germination in Lycopersicon. Theor. Appl. Genet. 81:321-326.

Garcia-Gomez, A., M.P. Bernal, and A. Roig. 2002. Growth of ornamental plants in two composts prepared from agroindustrial wastes. Bioresour. Technol. 83:81-87.

Guenzi, W.D., W.R. Kehr, and T.M. McCalla. 1964. Water-soluble phytotoxic substances in alfalfa forage: Variation with variety, cutting year and stage of growth. Agron. J. 55:499-500.

Herrera, F., J.E. Castillo, A.F. Chica, and L.L. Bellido. 2008. Use of municipal solid waste compost (MSWC) as a growing medium in the nursery production of tomato plants. Bioresour. Technol. 99:287-296.

Hochmuth, G.J., R.C. Hochmuth, R.K. Sprenkel, E.H. Simonne, D.D. Treadwell, T.W. Olczyk, and Y. Li. 2006. Adopting new plasticulture techniques to grow organic herbs in Florida greenhouses. Proc. Natl. Agricult. Plastics Congr. 33:11-15.

Jost, M.S. 2008. Solid state bioreactor method for production of compost water extract. MS thesis, Department of Horticulture, Michigan State University, East Lansing, MI

Koller, M., T. Alfoldt, M. Siegrist, and F. Werbel. 2004. A comparison of plant and animal based fertilizer for the production of organic vegetable transplants. Acta Hort. 631:209-215.

Kuepper, G. and K. Everett. 2004. Potting mixes for certified organic production. 3 Nov. 2010. <http:// www.attra.org/attra-pub/PDF/potmix.pdf $>$.

Li, Y.C., A.K. Alva, D.V. Calvert, and M. Zhang. 1998. A rapid nondestructive technique to predict leaf nitrogen status of grapefruit tree with various nitrogen fertilization practices. HortTechnology 8:81-86.

Liptay, A., S. Nicholls, and P. Sikkema. 1992. Optimal mineral nutrition of tomato transplants in the greenhouse for maximum performance in the field. Acta Hort. 319:489-492.

Masson, J., N. Tremblay, and A. Gosselin. 1991. Nitrogen fertilization and HPS supplementary lighting influence vegetable transplant production. I. Transplant growth. J. Amer. Soc. Hort. Sci. 116:594-598.

McEntee, K. 2005. National compost prices. 31 Oct. 2010. <http://www.recycle.cc/compostprices. pdf $>$.

Megie, C.A., R.W. Pearson, and A.E. Hiltbold 1967. Toxicity of decomposing crop residues to cotton germination and seedling growth. Agron. J. 59:197-199.

Melton, R. and R.J. Dufault. 1991. Nitrogen, phosphorus and potassium fertility regimes affect tomato transplant growth. HortScience 26 : 141-142.

Peet, M.M., E.S. Larrea, and C. Harlow. 2008. Tomato seed germination in organic mixes: Role of EC and mix components. Acta Hort. 797:393-398.

Perez-Murcia, M.D., J. Moreno-Caselles, R. Moral, A. Perez-Espinosa, C. Paredes, and B. Rufete. 2005. Use of composted sewage sludge as horticultural growth media: Effects on germination and trace element extraction. Commun. Soil Sci. Plant Anal. 36:571-582.

Ramana, S., A.K. Biswas, S. Kundu, J.K. Saha, and R.B.R. Yadava. 2002. Effect of distillery effluent on seed germination in some vegetable crops. Bioresour. Technol. 82:273-275.

Raviv, M., Y. Chen, and Y. Inbar. 1986. Peat and peat substitutes as growth media for containergrown plants, p. 257-287. In: Chen, Y. and Y. Avnimelech (eds.). The role of organic matter in modern agriculture. Martinus Nijhoff Publishers, Dordrecht, The Netherlands.

Sanchez-Monedero, M.A., A. Roig, J. Cegarra, M.P. Bernal, P. Noguera, and M. Abad. 2004 Composts as media constituents for vegetable transplant production. Compost Sci. Util. 12: 161-168.

Soval-Villa, M., C.W. Wood, and E.A. Guertal. 2002. Tomato leaf chlorophyll meter readings as affected by variety, nitrogen form, and nighttime nutrient solution strength. J. Plant Nutr. 25: 2129-2142.

Swiader, J.M. and A. Moore. 2002. SPAD-chlorophyll response to nitrogen fertilization and evaluation of nitrogen status in dry land and irrigated pumpkins. J. Plant Nutr. 25:1089-1100.

Theis, J.E. 2005. Effects of organic transplant potting media on tomato growth and root rhizosphere bacterial communities. 3 Nov. 2010. $<$ http:/ /vivo.cornell.edu/individual/vivo/individual21025>.

Treadwell, D.D., G.J. Hochmuth, R.C. Hochmuth, E.H. Simmone, L.L. Davis, W.L. Laughlin, Y. Li, T. Olczyk, R.K. Sprenkel, and L.S. Osborne. 2007. Nutrient management in organic greenhouse herb production: Where are we now? HortTechnology 17:461-466.

Uddling, J., J. Gelang-Alfredsson, K. Piikki, and H. Pleijel. 2007. Evaluating the relationship between leaf chlorophyll concentration and SPAD-502 chlorophyll meter readings. Photosynth. Res. 91:37-46.

Wang, Q., J. Chen, and Y. Li. 2004. Nondestructive and rapid estimation of leaf chlorophyll and nitrogen status of peace lily using a chlorophyll meter. J. Plant Nutr. 27:557-569.

Warncke, D.D. and D.M. Krauskopf. 1983. Greenhouse growth media: Testing and nutritional guidelines. Mich. State Univ. Coop. Ext. Bul. E-1736.

Watson, M.E. and J.R. Brown. 1998. pH and lime requirement, p. 13-16. In: Brown, J.R. (ed.). Recommended chemical soil test procedures. Missouri Agricultural Experiment Station, Columbia, MO.

Weston, L.A. and B.H. Zandstra. 1989. Transplant age and $\mathrm{N}$ and $\mathrm{P}$ nutrition effects on growth and yield of tomatoes. HortScience 24:88-90. 